\title{
Investigation on Mechanical Properties of Graphene Reinforced Jute Fibre Reinforced Polymer Composites
}

\author{
Rathinasabapathi $\mathrm{G}^{\mathrm{a}, 1}$, Krishnamoorthy $\mathrm{A}^{\mathrm{b}}$ \\ $a_{\text {Associate Professor, Department of Mechanical Engg, Panimalar Engineering }}$ \\ College, Chennai \\ ${ }^{b}$ Professor, Department of Mechanical Engineering, Sathyabama Institute of Science \\ \& Tech, Chennai
}

\begin{abstract}
In this study, the impact of adding Graphene Nano Platelets on the mechanical properties of Jute Fiber reinforced Polymer (JFRP) composites has been investigated. JFRP composite specimens were fabricated with varying number of layers (3 Layers, 4 Layers, and 5 Layers) and different orientations (30 degree, 45 degree, 60 degree) reinforced with $2 \%$ weight graphene nano platelet. Ultrasonicator is used for dispersion of graphene nano platelets into the epoxy matrix. Mechanical Tests namely Tensile test, flexural test and impact test is carried out to study the behavior of JFRP with different layers and orientations. The results proved that the use of $2 \%$ weight of Graphene Nano platelets led an enhancement in fatigue strength and impact strength. Also it is found that 3 layered with 30 degree orientation composite specimens had better mechanical properties compared to 4 layered and 5 layered composite specimens.
\end{abstract}

Keywords : JFRP, Graphene, Layer, Orientation, Mechanical Properties

\section{Introduction}

Jute Fiber is a natural fiber known for its versatility and also a 100\% bio-degradable. Jute fibers are environmental friendly and recyclable one. Jute also known as golden and vegetable fiber that is easily available at affordable cost. Due to it, researchers are interested in replacing conventional fibers with jute natural fibers. The properties of jute fibers that attract the industrialists are as follows. 1. Good insulating properties, 2. Low thermal conductivity, 3. Moisture regains.

These fibers are used in manufacturing mail bags, camp beds, Tarpaulin, motor linings, wrappings. A technique of dispersing graphene in the matrix improves thermal and mechanical properties. The major drawback of jute fibers is its brittleness. To enhance the property of ductility, graphene nano platelets are dispersed in the matrix. The natural jute and graphene matrix polymer composites can be used in industries due to

its light weight, superior mechanical property and stability of thermal property. Graphene is found to improve the machinability of jute fiber epoxy composite and

\footnotetext{
${ }^{1}$ Rathinasabapathi G: ${ }^{\mathrm{a}}$ Associate Professor, Dept of mrchanical Panimalar Engineering College, Chennai;

Email id: rajansaba@gmail.com
} 
also reduces delamination of composites.Graphene nano platelets are scattered by nano level technique for uniform dispersion in jute fibers and its exceptional properties enhance the electrical properties of composites.

The testing is done by increasing the thickness in varying number of layers and by varying orientations.

The mechanical testing is carried by varying weight percentages of multi walled carbon nano tubes and declared that bidirectional woven glass fiber composite showed better mechanical results. Moreover when MWCNTs are dispersed more than $4 \%$ weight, agglomeration in composites occurred and hence the properties deteriorates. The properties of glass fiber reinforced with graphene are also studied. GFRP is investigated by varying graphene weight percentage and results proved that composites exhibit better mechanical properties when nano fillers are added at a smaller proportion. The investigations are carried out by utilizing glass fibers for reinforcement and concluded that the JFRP exhibits better properties but the strength of the bundle is decreased.

The objective of this study is to increase the ductility of the jute fiber by reinforcing graphene nano platelets with epoxy and to test the bundle strength by varying the orientations of the jute fibers reinforced with graphene.

\section{Experimental Methods}

\subsection{Materials Used}

Graphene Nano platelets with thickness of $0.7-7 \mathrm{~nm}$ with flake size of $6 \mu \mathrm{m}$ is used for reinforcement. An epoxy resin with low viscosity of density $1.2 \mathrm{~g} / \mathrm{cm}^{3}$ is mixed with curing agent i.e., hardener HY951.Jute fibers woven in a bidirectional manner with density $1.3 \mathrm{~g} / \mathrm{cm}^{3}$ and with young's modulus $26.5 \mathrm{GPa}$ is chosen.

\subsection{Fabrication Of Jfrp}

Epoxy resin LY5561 with low yield is ultrasonicated with hardener HY951 in the ratio of 10:1. Ultrasonicator is used for stirring and $2 \%$ weight graphene is added to the matrix. The ultrasonicator is stirred for 2 hours for better dispersion of graphene in the matrix. Then it is allowed to cool for 40 minutes at room temperature. A rectangular mould is prepared for fabricating jute fibers to test the mechanical properties as per ASTM standards. A layer of epoxy resin matrix is poured into the mould and then jute fibers with different orientations and layers are fabricated. 9 distinct specimens are fabricated incorporating with different layers ( 3 layers, 4 layers and 5 layers) and orientations $\left(30^{\circ}, 45^{\circ}\right.$ and $\left.60^{\circ}\right)$.

\section{Mechanical Testing}

\subsection{Tensile Test}

ASTM D638 standard is adopted for tensile test. Universal Testing machine (UTM) is used for carrying out the test. Three identical composite specimens were tested and the average results of it are obtained. Fracture toughness is termed as the ability of the 
material to absorb energy i.e., deform plastically before fracture. Fracture toughness can be calculated by

Fracture Toughness $=\frac{\sigma^{2} \Pi a}{E}$, Where $\sigma$ is the Stress in $\left(\mathrm{N} / \mathrm{mm}^{2}\right)$, a is the Crack Length in $\mathrm{mm}$ and $\mathrm{E}$, the Young's Modulus

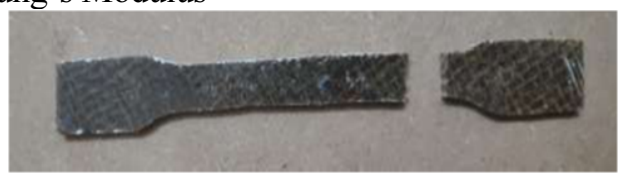

Figure 1. Tensile Test Specimen

\subsection{Flexural Test}

A Universal Testing Machine Adopting ASTM D790 Standard is used for flexural tests. The stiffness of the material is assessed by this test. Specimens with dimensions $127 \mathrm{~mm} \times 13 \mathrm{~mm} \times 3.2 \mathrm{~mm}$ is used for this test. Flexural Strength was calculated using the equation,

$$
\text { Flexural Strength }=\frac{3 P L}{2 b t^{2}}
$$

Where $\mathrm{P}$ is the break load or force in N, L is the support span in mm,b is the specimen width in $\mathrm{mm}$ and $\mathrm{t}$ is the specimen thickness in $\mathrm{mm}$.

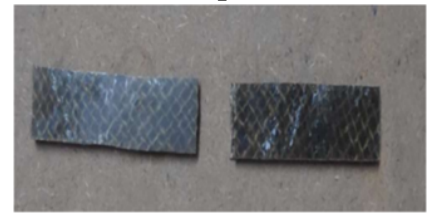

Figure 2. Flexural Test Specimen

\subsection{IMPACT TEST}

The impact strength of a material was determined by Izod Test. The impact of graphene reinforcement in JFRP is found. Specimens with standards following ASTM D256 are used by fabricating it with dimensions $70 \mathrm{~mm} \times 15 \mathrm{~mm} \times 3 \mathrm{~mm}$.

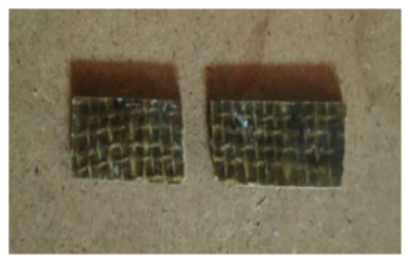

Figure 3. Impact Test Specimen 


\section{Results and Discussions}

\subsection{Tensile Test Reports}

The results of 9 identical jute fiber composite specimens carried out in UTM are listed below in the table. In order to increase the bundle strength, orientations are varied in the manner of $30^{\circ}, 45^{\circ}$ and $60^{\circ}$. The observations proved that fracture toughness decreased on varying fiber orientation beyond $30^{0}$. Reinforcement effect is not good in $45^{\circ}$ and $60^{\circ}$ orientation. Fracture toughness decreases on increasing layer thickness and by varying fiber orientation. Results showed that 3 layers with $30^{\circ}$ orientation exhibited better tensile strength. The table and graph lists various tensile properties with respect to layers and orientations.

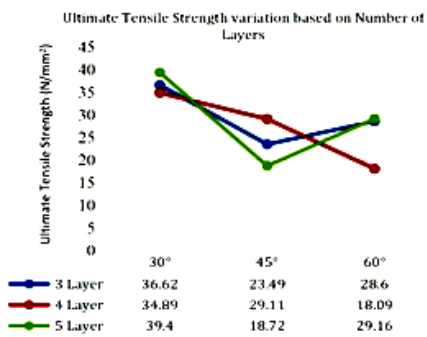

Figure 4. Tensile Fracture Strength based on Number of Layers

\subsection{Flexural Test Reports}

The results of flexural test for 9 different specimens are listed below in the table. The flexural strength of the JFRP is calculated by using the standard formulation. Observation and results were obtained for Jute fiber with fiber orientations 300, 450 and 600 and number of layers in JFRP (3 Layers, four Layers and 5 Layers). Results proved that 3 layered $30^{\circ}$ orientation JFRP exhibited better flexural strength compared to other JFRP specimens.

Table 1. Flexural Properties of JFRP

\begin{tabular}{|c|c|c|c|c|c|}
\hline $\begin{array}{c}\text { Sl. } \\
\text { No }\end{array}$ & Composition & $\begin{array}{c}\text { Ultimate } \\
\text { Break load } \\
(\mathrm{KN})\end{array}$ & $\begin{array}{c}\text { Displacement } \\
\text { Fmax (mm) }\end{array}$ & $\begin{array}{c}\text { Ultimate } \\
\text { Stress } \\
\left(\mathrm{KN} / \mathrm{mm}^{2}\right)\end{array}$ & $\begin{array}{c}\text { Flexural } \\
\text { Strength } \\
\left(\mathrm{N} / \mathrm{mm}^{2}\right)\end{array}$ \\
\hline 1. & $\begin{array}{c}3 \text { LAYERS } \\
30^{\circ}\end{array}$ & 0.185 & 2.400 & 0.003 & 36.2 \\
\hline 2. & $\begin{array}{c}3 \text { LAYERS } \\
45^{\circ}\end{array}$ & 0.220 & 2.000 & 0.002 & 28.43 \\
\hline 3. & $\begin{array}{c}3 \text { LAYERS } \\
60^{\circ}\end{array}$ & 0.185 & 2.900 & 0.002 & 33.1 \\
\hline
\end{tabular}




\begin{tabular}{|l|c|l|l|l|l|}
\hline 4. & $\begin{array}{c}4 \text { LAYERS } \\
30^{\circ}\end{array}$ & 0.235 & 2.300 & 0.003 & 38.7 \\
\hline 5. & $\begin{array}{c}4 \text { LAYERS } \\
45^{\circ}\end{array}$ & 0.200 & 2.600 & 0.002 & 34 \\
\hline 6. & $\begin{array}{c}4 \text { LAYERS } \\
60^{\circ}\end{array}$ & 0.270 & 1.600 & 0.003 & 30 \\
\hline 7. & $\begin{array}{c}5 \text { LAYERS } \\
30^{\circ}\end{array}$ & 0.265 & 2.300 & 0.003 & 31.7 \\
\hline 8. & $\begin{array}{c}5 \text { LAYERS } \\
45^{\circ}\end{array}$ & 0.145 & 1.700 & 0.002 & 20.3 \\
\hline 9. & $\begin{array}{c}5 \text { LAYERS } \\
60^{\circ}\end{array}$ & 0.175 & 2.100 & 0.002 & 29.5 \\
\hline
\end{tabular}

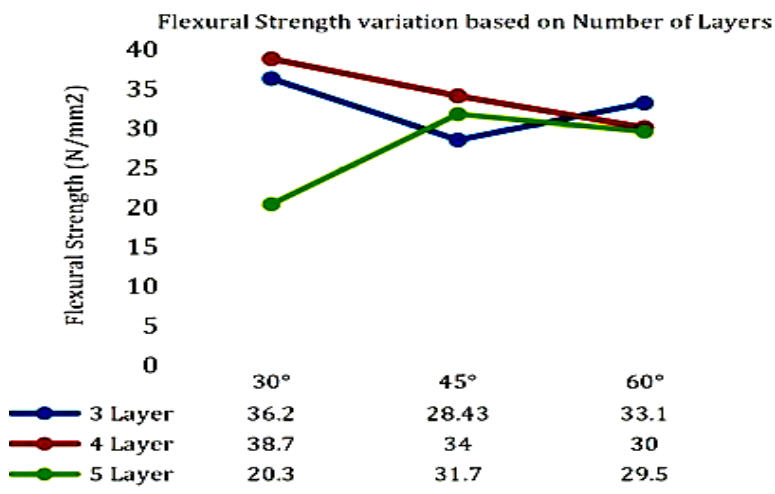

Figure 5. Flexural Strength based on Number of Layers

\subsection{Impact Test Reports}

The impact strength of the jute fiber specimens decrease with orientations beyond $30^{0}$ and also the same can be seen for layers beyond 3 layers in JFRP.

From the data inferred in the table below, it can be concluded that 3 layer with $30^{\circ}$ orientation exhibits improved impact strength and the impact strength diminish for $45^{\circ}$ $\& 60^{\circ}$ orientations. The impact strength diminish with increase in ply amid the same orientations,.

Table 2. Impact Properties of JFRP

\begin{tabular}{|c|c|}
\hline Sample I.D & Values in Joules \\
\hline 3 layer $30^{\circ}$ & 8.0 \\
\hline 3 layer $45^{\circ}$ & 6.2 \\
\hline
\end{tabular}




\begin{tabular}{|c|c|}
\hline 3 layer $60^{\circ}$ & 5.4 \\
\hline 4 layer $30^{\circ}$ & 4.8 \\
\hline 4 layer $45^{\circ}$ & 4.0 \\
\hline 4 layer $60^{\circ}$ & 3.2 \\
\hline 5 layer $30^{\circ}$ & 3.9 \\
\hline 5 layer $45^{\circ}$ & 3.1 \\
\hline 5 layer $60^{\circ}$ & 2.1 \\
\hline
\end{tabular}

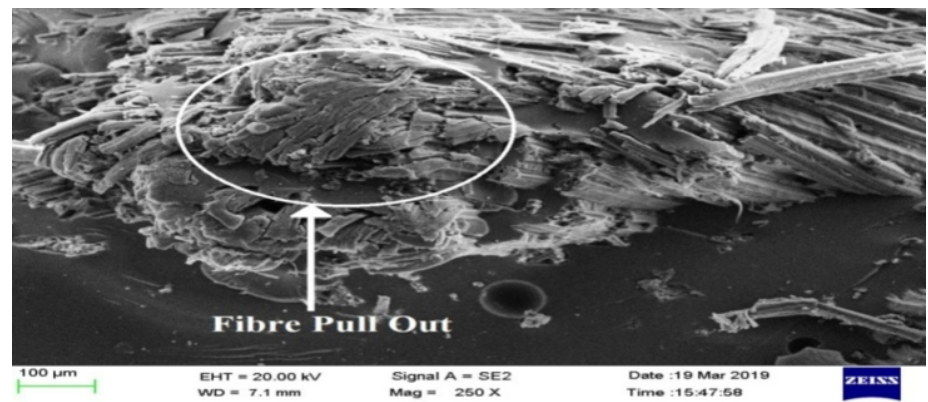

Figure 6. Fibre pull out in JUTE FIBER Reinforced Polymer with $60^{\circ}$ orientation

The morphological features are studied by SEM images. The fiber pull out can be seen in the image. When interfacial adhesion is not good, fiber pull out occurs. When the orientation is beyond $30^{\circ}$ delamination occurs and normally fiber gets pulled out from the matrix.

Fig.7shows the river lines when the load is applied and initiates crack propagation and lead to delamination. Fig8 shows that the graphene filler is not uniformly dispersed throughout the fiber. This leads to Agglomeration of Nano filler graphene ensuing in meager mechanical properties. The load carrying capability of the composite decreases due to agglomeration. 


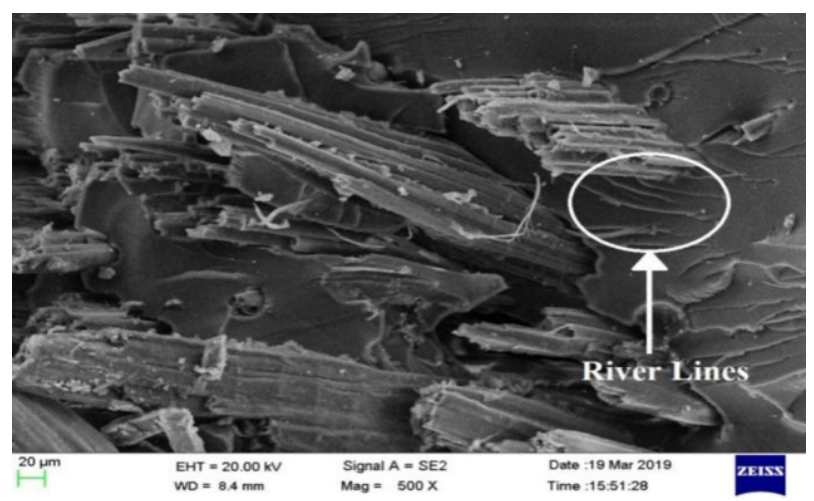

Figure 7. River Lines in JFRP

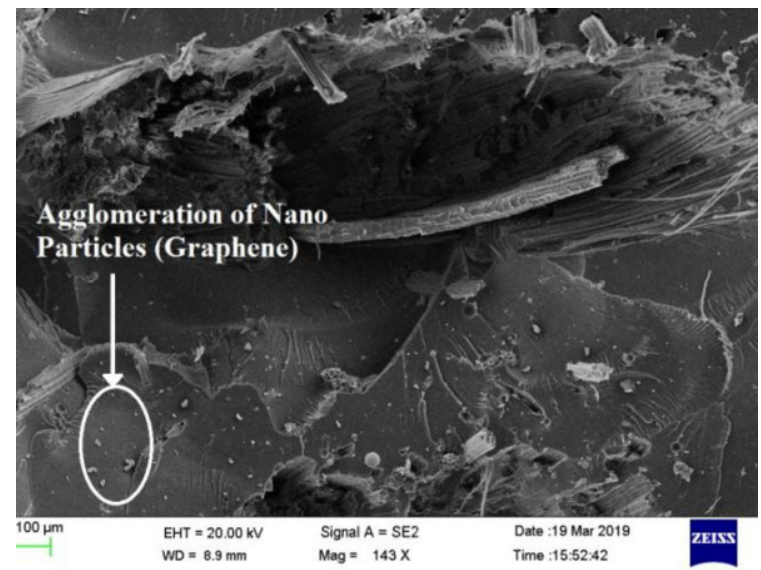

Figure 8. Agglomeration in JFRP

\section{Conclusion}

In general, Jute Fiber Reinforced Polymers are chosen due to its low weight which is alike in strength to other fibers. The Jute fiber reinforced polymer composites are incorporated with graphene with various Jute fiber orientations to further increase the bundle strength of JFRP. The Jute fiber specimens are fabricated and tested to acquire the mechanical properties.From the study 3 layer $30^{\circ}$ orientations jute fiber reinforced polymer with graphene weight of $2 \%$ gave a prominent stress-strain value and is suggested to get hold of superior strength, while specimens with $45^{\circ}$ and $60^{\circ}$ orientation resulted with lesser values of fracture toughness and flexural strength due to fiber pull out and agglomeration.

\section{References}

[1] S.A.Seth, I.S.Aji, A.Tokan. (2018). Effects of Particle size and loading on Tensile and Flexural properties of polypropylene reinforced doum palm shell particles composites. American scientific research journal for Engineering, Technology and sciences, Vol.44, Issue 1, 231 - 239. 
[2] S.I.Durowaye, G.I.Lawal, O.I.Olagbaju. (2014). Microstructure and Mechanical Propoerties of Sisal Particles reinforced polypropylene Composite. International Journal of Composite Materials, Vol.4 Issue 4, $190-195$.

[3] Rathinasabapathi.G, Krishnamoorthy.A. (2019). Exploration of Nano Fillers (Multi Walled Carbon Nano Tubes and Graphene Powders) in the Reinforcement of Epoxy/Glass Fibre Polymers (GFRP). International Journal of Innovative Technology and Exploring Engineering, Vol.8, Issue 12, 2718 2722 .

[4] Konstantinos Karvanis, Sona Rusnakova, Milan Zaludek, AlexanderCapka. (2018). Preparation and Dynamic Analysis of glass or carbon fiber/Polymer composites. Materials Science and Engineering 362, 012005. Doi:1088/1757-899X/362/1/012005.

[5] R.Murugan, R.Ramesh, K.Padmanabhan. (2014). Investigation on Static and Dynamic Mechanical Properties of Epoxy based woven Fabric Glass/ Carbo Hybrid Composite Laminates. Procedia Engineering, 97, $459-468$.

[6] P. Vimalanathan, N. Venkateshwaran, S. P. Srinivasan, V. Santhanam, M. Rajesh. (2017). Impact of surface adaptation and acacia nilotica bio filler Onstatic and dynamic properties of sisal fiber composite. International Journal of Polymer analysis and characterization. DOI: 10.1080/1023666X.2017.1387689.

[7] Rathinasabapathi.G, Krishnamoorthy.A. (2019). Reinforcement Effect of Graphene Enhanced Glass Fibre Reinforced Polymers: A Prominence on Graphene Content. Digest Journal of Nanomaterials and Biostructures, Vol.14, No.3, $641-653$.

[8] H.Sezgin, O.B.Berkalp, R.Mishra, J.Militky. (2016). Investigation of dynamic mechanical properties of jute/carbon reinforced composites. International journal of Materials and Metallurgical Engineerng, Vol.10, Issue 12, $1492-1495$.

[9] Daiane Romanzini, Alessandra Lavoratti, Heitor L.Ornaghi Jr., Sandro C.Amico, Ademir J.Zattera. (2013). Influence of fiber content on the mechanical and dynamic mechanical properties of glass/ramie polymer composites. Materials and Design 47, 9 -15.

[10]Umer R, Li Y, Dong Y et al. The effect of graphene oxide (GO) nanoparticles on the processing of epoxy/glass fiber composites using resin infusion.International Journal of Advanced Manufacturing Technology 2015 (81)2183-2192. 